Original Article

\title{
Study on the Influence of Processing Oil on the Physical Mechanical Properties and Adhesion of Ethylene Propylene Diene Monomer (EPDM) Rubbers to Polyester Fabrics
}

\author{
Nguyen Thanh Liem*, Nguyen Pham Duy Linh, Nguyen Huy Tung, \\ Bach Trong Phuc, Bui Chuong, Nguyen Thi Thuy \\ Hanoi University of Science and Technology, No. 1, Dai Co Viet Street, Hai Ba Trung Distric, Hanoi, Vietnam
}

Received 31 December 2019

Revised 16 March 2020; Accepted 08 April 2020

\begin{abstract}
In this paper, the influence of paraffinic oil on the physical mechanical and thermal properties of three EPDM rubbers types Buna EP T.6465, Keltan 5260 Q and Keltan 6160 D have been investigated. The results showed that the tensile strength and the elongation at break of Keltan 5260 Q and Keltan 6160 D with 10 phr paraffinic oil represent the improvement of 57.8\% to 57.6\% and $71 \%$ to $81 \%$ respectively, compared to EPDM rubbers without paraffinic oil. The mean peel force of EPDM keltan 6260D with $10 \mathrm{phr}$ paraffinic oil loaded is about $36 \%$ and $32.5 \%$ higher than that of keltan 5260 Q and EP.T 6465 respectively. Beside that at the suitable paraffinic oil contents, the thermal resistance of Keltan 5260 Q and 6160 D seems to be a little higher than that of without processing oil and these EPDM rubbers are suitable for application to high thermal resistance rubber products.
\end{abstract}

Keywords: EPDM rubbers, processing oil, mechanical property, thermal aging.

\section{Introduction}

The rubbers for conveyor belts manufacturing must have high elasticity, frictional properties as well as the high load bearing property. Besides it, rubber also have to get other outdoor properties like high heat resistance, flame retardant, good adhesion to reinforcement fiber etc, depending on belt working conditions. Conforming to these needs, rubbers compound consisted of various materials such as vulcanizing agents, carbon black, accelerators, retardant, processing oils in different compositions.

EPDM is obtained by polymerizing ethylene and propylene with a small amount of a nonconjugated diene [1,2]. EPDM have good aging characteristics, good weathering oxidation

\footnotetext{
* Corresponding author.

Email address: liem.nguyenthanh@ @ust.edu.vn

https://doi.org/10.25073/2588-1140/vnunst.4986
} 
and chemical resistance. These superior properties of EPDM consisted of saturated polymer chain that accounts for its great resistance to oxygen, heat, and ozone as compared to NR, butadiene rubber (BR), and styrene butadiene rubber (SBR). The disadvantages of EPDM are poor adhesion to many substrate and hard to well mix with fillers and additives. The use of EPDM rubber has become increasingly demanded due to its excellent performance, especially in industrial application such as tube, mounts, conveyor belt, seals $[3,4]$. The EPDM rubber manufacturers supply many EPDM grades but always with no oil extended in markets, different type of third monomer for wide range of applications.

Many studies have dealt with the relationship between morphology, processing, and the physical, rheological and mechanical properties of EPDM blends in order to overcome the EPDM disadvantages. Suma et al. [5] reported that the effect of precuring the slower curing rubber (EPDM in NR/EPDM) as a possible route to attain a covulcanized state in NR/EPDM, thus resulting in an improvement of the mechanical properties. Botros and Sayed investigated the effect of different blend compositions of NR/EPDM on the swelling behavior of the blend in motor oil under compression strain [6]. Other researchers investigated the influence of some paraffinic oils on rheological properties, dynamic properties, and behavior at low temperature of various EPDM compounds and found out the relationship of oil characteristics with EPDM properties $[7,8]$.

Basically controlled processing oil content can be steered to give a good balance of processing, such as efficient mixing, fast extrusion and good collapse resistance of thin walled profiles, and excellent cured physical properties.

In the present research, the effect of paraffinic oil loading on mechanical and adhesion properties of three types EPDM before and after heat aging was investigated.

\section{Materials and Methods}

\subsection{Materials}

EPDM rubber type Keltan 5260 Q and Keltan 6160 D (Lanxess-Germany) with ethylene contents of $62 / 64 \%$, diene of $2.3 / 1.2 \%$, ML $(1+4)$ at $125^{\circ} \mathrm{C}$ of $55 / 63 \mathrm{MU}$ and oil contents of $0 \%$ correlatively, were used as the neat rubbers. EPDM Buna EP T.6465 (Arlanxeo - Netherland) with ethylene contents of $64 \%$, diene of $4.0 \%$, ML $(1+4)$ at $125^{\circ} \mathrm{C}$ of $37 \mathrm{MU}$ and oil contents of $33.3 \%$ was used as control rubber. Zinc oxide, accelerators TMTD and MBTS, antioxidants vulkanox 4020, carbon black (HAF-N330), resin EM 331 and dicumyl peroxide (DCP) was commercial grade from China.

Paraffinic oil with density of $0.98 \mathrm{~g} / \mathrm{cm}^{3}$, viscosity of 20-40 cst, polyester fabric covered with resorcinol resin (density $200 \mathrm{~g} / \mathrm{m}^{2}$ ) was commercial grade from China. All chemical were used as received without any purification and dried to constant weight before mixing.

\subsection{Methods}

\subsubsection{Kneading and vulcanization conditions}

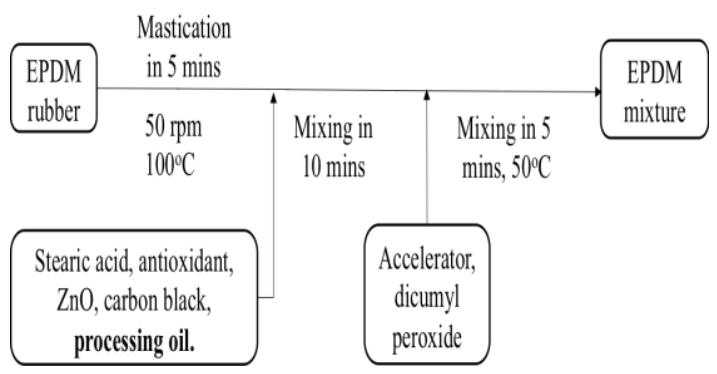

Figure 1. Preparation and kneading process.

A conventional vulcanization system is used for the rubber. Rubber compound as showed in Table 1 is mixing in Brabender internal mixer (Plasti-corder ${ }^{\circledR}$ Lab-Station W50-EHT) working at temperature of $100^{\circ} \mathrm{C}$ and rotator speed of 50 $\mathrm{rpm}$. The EPDM rubber is masticated for 5 mins before other ingredients like stearic acid, antioxidant, $\mathrm{ZnO}$, oil and carbon black are added and mixing is continued for another 10 mins. 
Before running through the two-roll machine to make the sheet, the accelerator and curing agent (DCP) are added and the rubber compound is kept mixing for 5 mins. The rubber sheets are vulcanized in the hydraulic press at $160^{\circ} \mathrm{C}$ and $100 \mathrm{~kg} / \mathrm{cm}^{2}$ pressure for suitable time and then keeping at room temperature for 24 hours before testing.

Table 1. Composition of the rubber compound

\begin{tabular}{|l|c|}
\hline \multicolumn{1}{|c|}{ Ingredient } & Content, phr \\
\hline EPDM & 100 \\
\hline ZnO & 5.0 \\
\hline Stearic acid & 1.5 \\
\hline HAF N330 & 40 \\
\hline Vulkanox 4020 & 1.5 \\
\hline TMTD & 2.0 \\
\hline MBTS & 1.5 \\
\hline EM 331 resin & 3 \\
\hline Dicumyl peroxide & 2.5 \\
\hline Paraffinic oil & $0-15$ \\
\hline
\end{tabular}

\subsubsection{Analytical techniques}

By using a Rotor less Rheometer RLR - 4 (Japan), at $160 \pm 1 \mathrm{C}$, according to ASTM D2084-95, the curing process of rubber compound is investigated. The mixing energy of each compound is recorded. The cure characteristics: $\mathrm{Ml}$ (minimum torque), $\mathrm{MH}$ (maximum torque), $\mathrm{t}_{\mathrm{c} 90}$ (optimum cure time) and $\mathrm{t}_{\mathrm{s} 2}$ (scorch time) are registered. The dumbbellshaped samples for tensile and elongation test were cut from the molded rubber sheets according to TCVN 4509-2006. The specimen dimension was $115 \times 25 \times 2.5 \mathrm{~mm}$ with gauge length of $33 \pm 1 \mathrm{~mm}$ as showed in Figure 2:

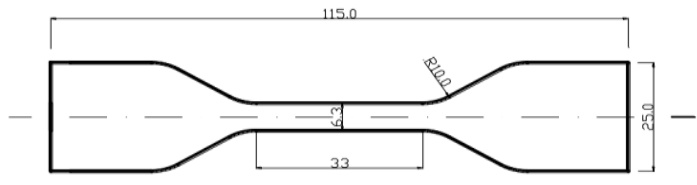

Figure 2. Dumbbell-shaped sample.

Tensile strength and elongation at break are determined on an Instron 5582 universal testing machine with a crosshead speed of $300 \mathrm{~mm} / \mathrm{min}$, according to TCVN 4509-2006. The elongation at break is the percentage change in gauge length from original to rupture and is calculated as followed:

$$
\left.\mathrm{E}_{\mathrm{b}}=\left(1_{1}-1_{0}\right) / 1_{0} \times 100 \% \quad \text { (Eq. } 1\right)
$$

Where:

$\mathrm{E}_{\mathrm{b}}$ : elongation at break, \%

$1_{0}$ : gauge length before testing, $\mathrm{mm}$

$1_{1}$ : gauge length of sample before breaking, $\mathrm{mm}$.

Modulus is the force at a specific elongation value, in this case is $300 \%$ elongation (is referred to as M300). The force and elongation were recorded in tensile curve and M300 was calculated using the quotation 2 :

$$
\mathrm{M}=\mathrm{F} / \mathrm{E} \quad \text { (Eq. 2) }
$$

Where:

M: Modulus at $300 \%$ elongation, $\mathrm{MPa}$

F: Tensile force at $300 \%$ elongation, Psi

E: Elongation at $300 \%$ of gauge length, mm

The hardness test is carried according to TCVN 1959-88 on TECHLOCKTGS 709N equipment. The adhesion between rubber and polyester fabric is determined through the peel test according to ISO 252: 2007 standard.

Sample for peel test is of size $25 \mathrm{~mm}$ wide and $200 \mathrm{~mm}$ length. A rubber layer was placed on the polyester fabric, the anti - stick film of maximum $100 \mathrm{~mm}$ length was placed between rubber sheet and fabric so as to permit a length of at least $100 \mathrm{~mm}$ to be stripped. The value of adhesion is calculated as the equation 3 :

$$
\mathrm{P}=\mathrm{F} / \mathrm{W} \quad \text { (Eq. 3) }
$$

Where: P: Peel strength, N/mm

$F$ : averaged force during testing, $\mathrm{N}$

$\mathrm{W}$ : specimen width, $\mathrm{mm}$

Aging test is carried in oven at $150^{\circ} \mathrm{C}$ for 168 hours according to ISO 4195:2012.

The fractured surfaces of the test specimens were observed by scanning electron microscopy (SEM) using a Jeol JSM-6360LV, Japan. Prior to the SEM observations, all the samples were coated with a thin layer of platinum to avoid the build-up of an electrical charge. 


\section{Results and Discussions}

\subsection{Effect of paraffinic oil loading on the mechanical properties of vulcanizates}

Figure 3 and Table 2 summarized the rheological behavior of three types EPDM rubbers. The obtained data shows that the EPDM EP.T 6465 has minimum torque and maximum torque is of keltan $6160 \mathrm{D}$ and $5260 \mathrm{Q}$. It can be seen that the minimum torque which reflects the lower viscosity of compound with the increasing amount of oil in the composition.

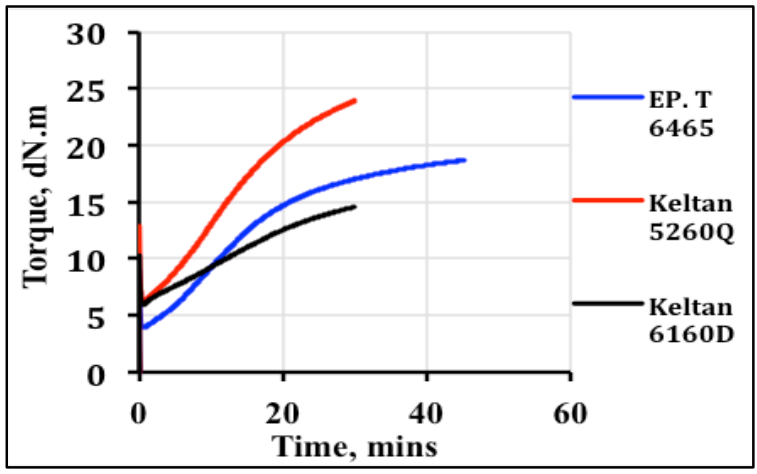

Figure 3. Rheological behavior of uncured rubbers.

Table 2. The rheological values of compounds

\begin{tabular}{|l|l|l|l|l|l|}
\hline Sample & $\begin{array}{l}\text { MH, } \\
\text { dN.m }\end{array}$ & $\begin{array}{l}\text { ML, } \\
\text { dN.m }\end{array}$ & $\begin{array}{l}\text { Tc10, } \\
\text { min }\end{array}$ & $\begin{array}{l}\text { Tc90, } \\
\text { min }\end{array}$ & $\begin{array}{l}\text { CR, } \\
\text { min }\end{array}$ \\
\hline $\begin{array}{l}\text { EP.T } \\
\text { 6465 }\end{array}$ & 19.52 & 3.92 & 4.25 & 37.13 & 32.88 \\
\hline $\begin{array}{l}\text { Keltan } \\
\text { 5260 Q }\end{array}$ & 23.91 & 6.22 & 3.81 & 24.28 & 20.46 \\
\hline $\begin{array}{l}\text { Keltan } \\
\text { 6160 D }\end{array}$ & 14.57 & 5.96 & 2.60 & 25.0 & 22.40 \\
\hline
\end{tabular}

The influence of oil load on the mechanical properties of the rubber compound has been investigated and shown in Figure 4, Figure 5 and Figure 6. The oil loading content are 5, 10 and 15 phr. compared to neat EPDM rubber. The EPDM type Buna EP T.6465 already have 33.3 $\%$ processing oil was used as control sample and used without adding any paraffinic oil. The results in Figure 4, 5 and 6 showed that the tensile strength and elongation at break of both Keltan 5260 Q and Keltan 6160 D have sharply upward trend in increasing oil loading from 5 to $10 \mathrm{phr}$. but the hardness. This improvement of tensile strength and elongation at break is due to the present of paraffinic oil in rubber compound that made the rubber backbone become more flexible.

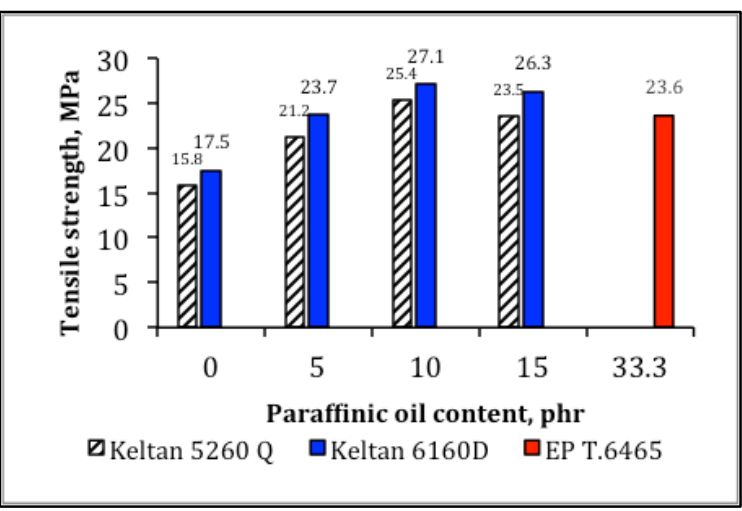

Figure 4. The influence of oil loaded to tensile strength.

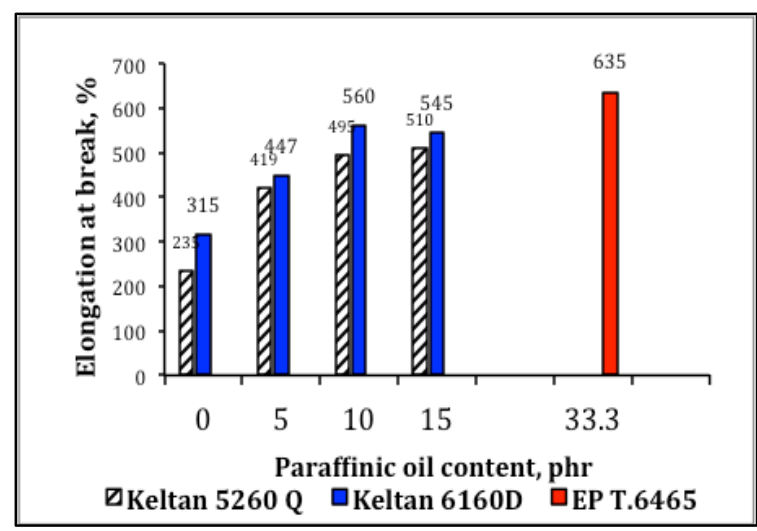

Figure 5. The influence of oil loaded to elongation at break.

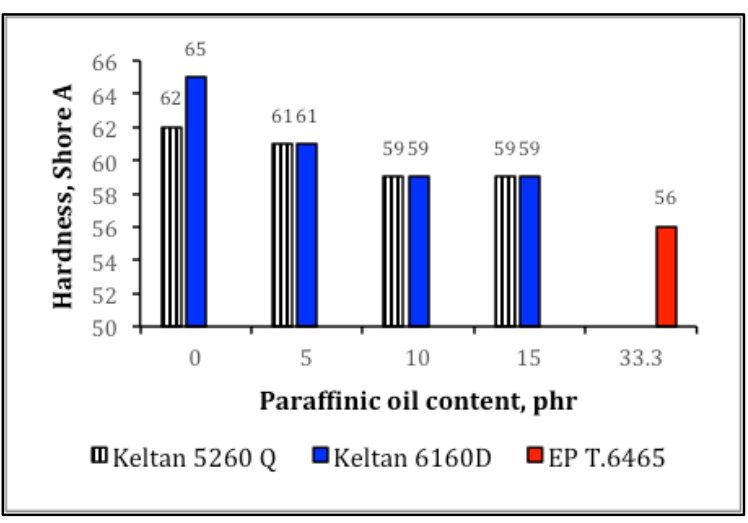

Figure 6. The influence of oil loading to hardness. 
Beside that, with suitable paraffinic oil as processing agent in this case is 10 phr., could bring into play all additives, filler in rubber compound by better mixing. It is found that with 10 phr. of oil in compound of both Keltan 5260 Q and Keltan 6160 D the tensile strengths (25.4 and 27.1 Mpa) are much higher then that of EP T.6465 (23.6 Mpa). With $10 \%$ oil loading, the elongations at break increased significally, two times higher than that of neat rubbers, reached $552 \%$ and $570 \%$ compared to $322 \%$ and $315 \%$ of samples without oil.

It also can be seen that the mechanical properties of two neat rubber have gently downward in the increasing of oil loading, in this case is 15 phr. Tensile strengths of Keltan 5260 $\mathrm{Q}$ and 6160 D decreased from 25.4 Mpa and 27.1 Mpa to 23.5 Mpa and 26.3 Mpa correlatively but still higher than that of EP T.6465 (23.6 Mpa). It can be explained that the extra oil content reduced crosslinking densities of rubber compound and that lead to reduce the mechanical properties.

In the present of paraffinic oil, the rubber backbone of two rubber matrixes become more flexible and the lower hardness can be explained is due to the lower molecular interactions. The $10 \mathrm{phr}$. oil contents are chosen for the next study.

\subsection{Effect of paraffinic oil loading on the thermal aging of EPDM rubber}

The rubber products, specially EDM rubber, silicon rubber or EPDM rubber may be used in high temperature such as conveyor belt, degradation of rubber occur under heating, oxygen, steam, chemicals conditions and give changes in property values. In order to be able to handle hot materials such as cement, clinker, sintered ore etc. the rubber materials needed to withstand harsh working environments for long serving time, the aging condition is chosen as $150^{\circ} \mathrm{C}$ for 168 hours. The percentage changes in the tensile strength of EPDM Keltan 5260 Q and
Keltan $6160 \mathrm{D}$ compounds at $150^{\circ} \mathrm{C}$ for 168 hours are shown in Table 3.

Table 3. Changes in tensile strength of compounds with $10 \%$ oil after thermal aging

\begin{tabular}{|c|c|c|c|c|c|}
\hline \multirow{2}{*}{$\begin{array}{c}\text { Time, } \\
\text { hours }\end{array}$} & \multicolumn{5}{|c|}{ Retention } \\
\cline { 2 - 6 } & S1 & S2 & S3 & S4 & S5 \\
\hline 0 & 1.0 & 1.0 & 1.0 & 1.0 & 1.0 \\
\hline 24 & 0.87 & 0.98 & 0.86 & 0.95 & 0.95 \\
\hline 48 & 0.83 & 0.94 & 0.81 & 0.90 & 0.89 \\
\hline 72 & 0.64 & 0.90 & 0.67 & 0.87 & 0.86 \\
\hline 96 & 0.62 & 0.85 & 0.58 & 0.85 & 0.82 \\
\hline 120 & 0.58 & 0.83 & 0.51 & 0.78 & 0.80 \\
\hline 144 & 0.55 & 0.82 & 0.43 & 0.76 & 0.69 \\
\hline 168 & 0.48 & 0.79 & 0.35 & 0.71 & 0.65 \\
\hline
\end{tabular}

\section{Designations:}

\section{S1: EPDM Keltan 5260 Q without oil}

S2: EPDM Keltan 5260 Q with $10 \%$ oil

S3: EPDM Keltan 6160 D without oil

S4: EPDM Keltan 6160 D with $10 \%$ oil

S5: Control sample EP T.6465 with $33.3 \%$ oil

The results in Table 3 showed that after 144 hours aging in $150^{\circ} \mathrm{C}$, the aging ratio or retention of three rubber compounds with oil (S2, S4 and S5) reduced from $25 \%$ to $35 \%$. But after 168 hours the different of aging ratio of three compounds can be seen.

After 168 hour at $150^{\circ} \mathrm{C}$ the retention of EPDM Keltan 5260 Q with 10 phr oil (S2) reached 0.79 , much higher than one without oil (S1 - 0.48) and higher than EPDM Keltan 6160 D (S4) and control sample (EP T.6465 - S5). The retention of compounds with $10 \%$ oil loaded (S2, S4) is also much higher (from $165 \%$ to $200 \%$ ) than neat rubber (S1, S3). The aging ratio are in descending order from Keltan 5260 Q, Keltan $6160 \mathrm{D}$ and EP T.6465, that mean the heat resistance of EPDM Keltan 5260 Q is best. The other mechanical properties of three compounds after aging are showed in Table 4. 
Table 4. Retention in mechanical properties of compounds at $150^{\circ} \mathrm{C}$ for 168 hours

\begin{tabular}{|c|l|c|}
\hline Compound & \multicolumn{1}{|c|}{$\begin{array}{c}\text { Mechanical } \\
\text { properties }\end{array}$} & Retention \\
\hline \multirow{4}{*}{ Keltan 5260 Q } & Tensile strength & 0.81 \\
\cline { 2 - 3 } & Modulus M300 & 0.84 \\
\cline { 2 - 3 } & Elongation at break & 0.75 \\
\cline { 2 - 3 } & Hardness & 1.03 \\
\hline \multirow{5}{*}{ Keltan 6160 D } & Tensile strength & 0.79 \\
\cline { 2 - 3 } & Modulus M300 & 0.84 \\
\cline { 2 - 3 } & Elongation at break & 0.73 \\
\cline { 2 - 3 } & Hardness & 1.03 \\
\hline & Tensile strength & 0.65 \\
\cline { 2 - 3 } EP T.6465 & Modulus M300 & 0.86 \\
\cline { 2 - 3 } & Elongation at break & 0.69 \\
\cline { 2 - 3 } & Hardness & 1.05 \\
\hline
\end{tabular}

The differences in mechanical properties of EPDM keltan rubber $5260 \mathrm{Q}$ and $6160 \mathrm{D}$ before and after thermal aging can be explained as follows: EPDM keltan $6160 \mathrm{D}$ has higher ethylene content and higher molecular weight (64\% ethylene and ML 63 MU) than 5260 Q
(62\% ethylene and $55 \mathrm{MU}$ ). Due to the difference in molecular structure, the mechanical properties of EPDM rubber keltan $6160 \mathrm{D}$ before aging are higher than that of keltan 5260 Q.

But the percentage change in properties after thermal aging of two rubbers is explained by the third monomers used. Ethylene norbornene (ENB) used in keltan $5260 \mathrm{Q}$ is more heat resistant compared to dicyclopentadiene (DCPD) used in $6160 \mathrm{D}$ keltan rubber.

The highest change in mechanical properties after aging of control sample (S5) EP T.6465 is explained by the high ENB content $(4.0 \pm 0.6)$ and high paraffinic oil content (33.3\%). The high double bond content in ENB together with the large amount of oil, which is able to escape under the effect of heat, resulted in reducing the properties of the sample.

The influence of processing oil in EPDM rubbers is confirmed by morphology observation with Scanning Electron Microscopy (SEM) as showed in Figure 7.

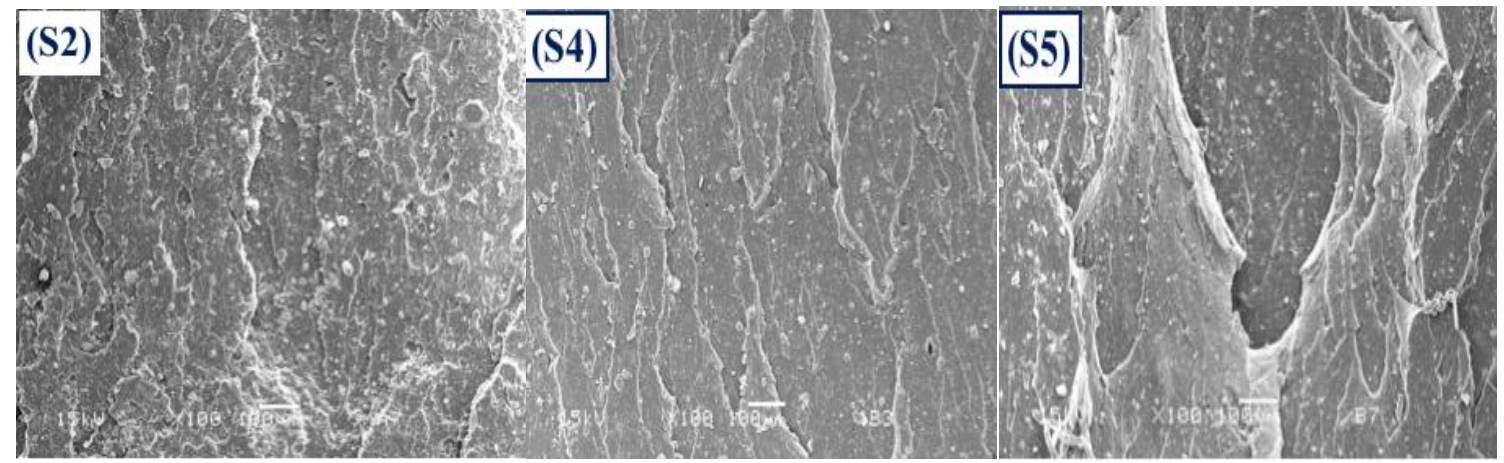

Figure 7. SEM photographs of EPDM rubber surface after heat aging.

From Figure 7, we can see that the smoother surface of EPDM rubber type Keltan 5260 Q (S2) when compared with Keltan 6160 D (S4) and there are no sign of crack formation after 168 hours at $150^{\circ} \mathrm{C}$. The larger voids appeared on the surface of S5 (EP T.6465) compound and the compound seems to be more brittle after 168 hours. That can be explained that the EPDM type EP T.6465 have much oil content in compound and the oil may leaked out of compound during high temperature and make a voids as can be seen in Figure 7 (S5).

\subsection{Effect of paraffinic oil loading on the adhesion properties of EPDM rubbers to polyester fiber}

For the compound for high heat resistance conveyor belt, the adhesion is the most importance character. The adhesion of three type EPDM rubber to polyester fabric before aging are showed in Figure 8. 

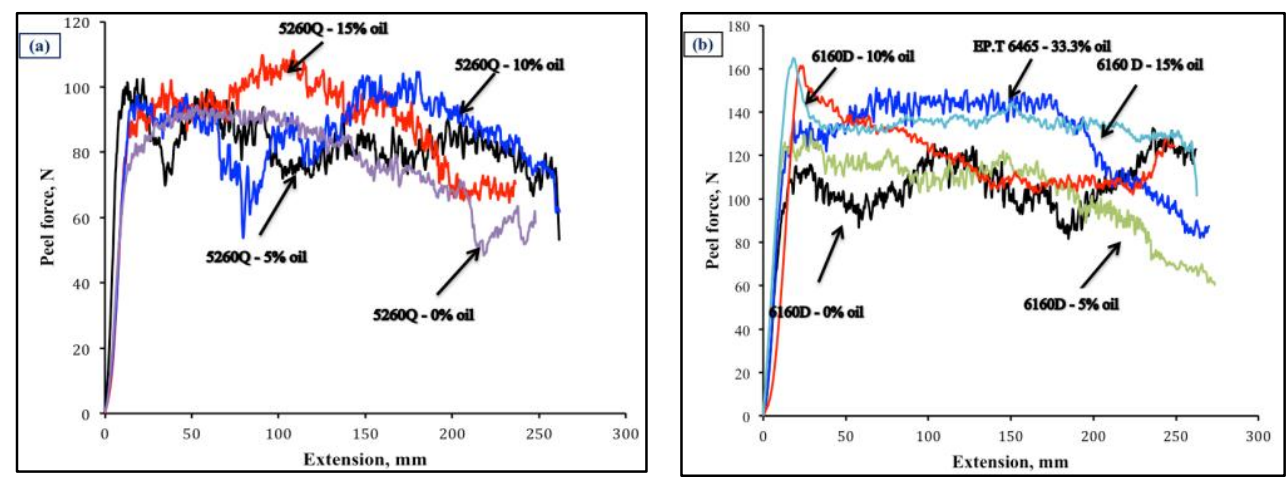

Figure 8. Peel force of EPDM rubbers to polyester fabric (a) Keltan 5260 Q, (b) keltan 6160 D/EP.T645.

From Figure 8 we can see the trend of peel force when increasing the oil content. The more oil loaded the higher peel force. The highest peel force at $164 \mathrm{~N}$ with 10 to $15 \%$ oil loaded in EPDM Keltan 6260D. The mean peel force of keltan $6260 \mathrm{D}$ with $10 \%$ oil is about $36 \%$ and $32.5 \%$ higher than that of EPDM keltan $5260 \mathrm{Q}$ and EP.T 6465 respectively. It can be explained due to the structure of two rubbers. EPDM keltan $6160 \mathrm{D}$ have medium molecular weight distribution
(MMD3.5-4.0) compared with narrow molecular weight distribution of Keltan 5260 Q (MMD 2.0 - 2.5). Branching is the most important method for steering MWD of rubber. Higher branching corresponds to lower Delta $\delta(\Delta \delta)$ giving lower viscosity at higher shear rates that lead keltan $6160 \mathrm{D}$ easier to come to fabric layers and have higher peel force. SEM photos in Figure 9 confirm the influence of oil loaded on adhesion of rubbers to polyester fabric.
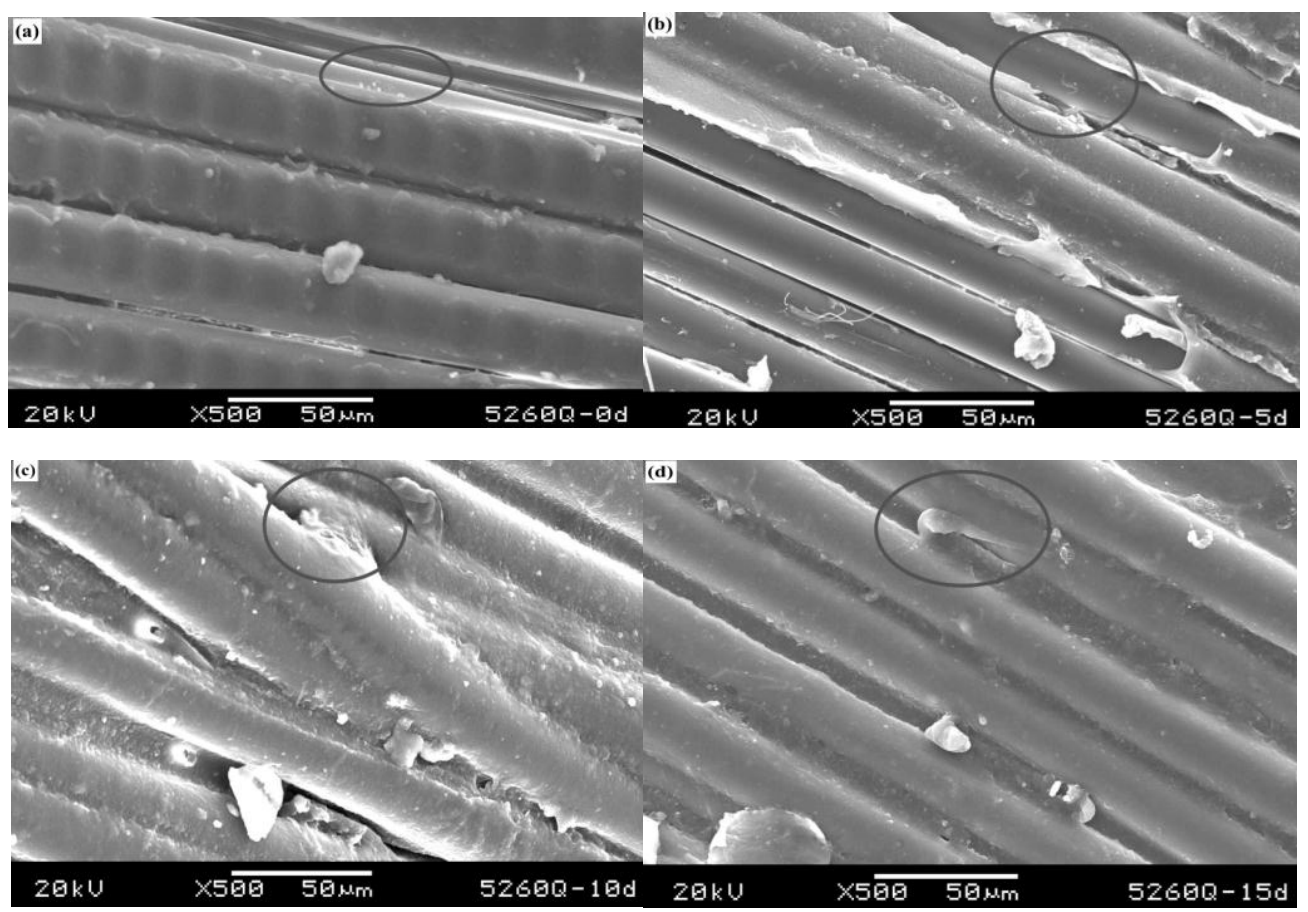

Figure 9. SEM photographs of polyester fabric surface with different oil load.

(a): sample with no oil; (b): sample with 5\% oil; (c): sample with $10 \%$ oil; (d): sample with $15 \%$ oil. 
The results in Figure 9 show the evident that the rubber is pulled out of fabric (Figure 9 (a) and (b)) to denote the poor adhesion. With $10 \%$ to $15 \%$ oil loaded, the rubber seem to have good adhesion to fabric, here are no evident of rubber pulled out but the crack is in rubber phase (Figure 9 (c) and (d)).

\section{Conclusion}

The processing oil content, in this case is paraffinic oil, have significantly effected to EPDM rubber mechanical properties. It have been found that the suitable oil content in EPDM rubbers type Keltan 5260 Q and Keltan 6160 D is 10 wt.\%. With 10 wt.\% paraffinic oil loaded the tensile strength values and elongation at break of Keltan 5260 Q and Keltan 6160 D before aging represent the improvement of $57.8 \%$ to $57.6 \%$ and $71 \%$ to $81 \%$ respectively, compared to a virgin EPDM rubbers. The mechanical properties of EPDM before aging increase in order from EP T.6465, Keltan 5260 Q and Keltan 6160 D. But after aging at $150^{\circ} \mathrm{C}$ in 168 hours, rubber EPDM Keltan 5260 Q and $6160 \mathrm{D}$ showed the same aging ratio but much better than EP T.6465. The EPDM rubber type Keltan 6160 D with 10 wt.\% of oil is chosen and suitable for thermal resistance rubber applications.

\section{Acknowledgements}

This research is funded by Ministry of Science and Technology (MOST) under grant number KC.02.10/16-20. Authors thank the staff of Centre for Polymer Composite and Paper Technology (HUST) for precious help with laboratory analyses. Furthermore, special thanks go to editors and anonymous referees for their constructive and critical reviews of our manuscript.

\section{References}

[1] Iraj Rezaeian, Payam Zahedi, Ali Rezaeian, Rubber adhesion to different substrates and its importance in industrial applications: A review, Journal of Adhesion Science and Technology 26 (6) (2012) 721-744. https://tandfonline.com/doi/ abs/10.1163/016942411X579975.

[2] Neelesh Ashok, Meera Balachandran, Falix Lawrence, Neethu Sebastian, EPDM-chlorobutyl rubber blends in $\gamma$-radiation and hydrocarbon environment: Mechanical, transport, and ageing behavior, Journal of Applied Polymer Science 134 (33) (2017) 381-392. https://doi.org/10.1002/app. 45195.

[3] Zhenhua Wang, Yonglai Lu, Jun Liu, Zhimin Dang, Liqun Zhang, Weimin Wang, Preparation of nano-zinc oxide/EPDM composites with both good thermal conductivity and mechanical properties, Journal of Applied Polymer Science 119 (2) (2011) 1144-1155. https://doi.org/10.1002/ app.32736.

[4] Martin Van Duin, Ramona Orza, Ron Peters, Victor Chechik, Mechanism of peroxide crosslinking of EPDM rubber, Macromolecular Symposia 292 (1) (2010) 66-74. https://doi.org/10. 1002/masy.201050508.

[5] N. Suma, Rani Joseph, K.E. George, Improved mechanical properties of NR/EPDM and NR/butyl blends by precuring EPDM and butyl, Journal of Applied Polymer Science 49 (3) (2003) 549 - 556. https://doi.org/10.1002/app.1993.070490318.

[6] S.H. Botros, A. Mounir El Sayed, Swelling behavior of NR/EPDM rubber blends under compression strain, Journal of Applied Polymer Science 82 (12) (2001), 3052-3066. https://doi.org/ 10.1002/app.2160.

[7] Tapan K. Bhaumik, Chanchal Neogi, B.R. Gupta, Anil K.Bhowmick, Abrasion of high temperature conveyor belt compounds based on ethylene propylene diene and bromobutyl rubber blends, Wear 128 (2) (1988) 167-178. https://doi.org/10. 1016/0043-1648(88) 90182-2.

[8] Gyung Soo Jeon, Enhancing the Adhesion Retention by Controlling the Structure of the Adhesion Interphase Between Rubber Compound and Metal. Part I. Effect of Cobalt Salt. Journal of Adhesion Science and Technology 23 (6) (2009) 913-930. https://doi.org/10.1163/156856109X411 256. 